\title{
ANÁLISE CLÍNICO-QUALITATIVA DO DISCURSO DE UMA CRIANÇA COM PARALISIA CEREBRAL
}

\author{
Giselle Massi* \\ Ana Cristina Guarinello \\ Ana Paula Santana \\ Roseli Paciornik ${ }^{\#}$
}

\begin{abstract}
RESUMO. Esse artigo propõe uma reflexão sobre a constituição processual de produções linguístico-discursivas de uma criança com paralisia cerebral, à luz de situações interativas. Apresenta o método clínico-qualitativo como forma de investigação e intervenção linguístico-discursiva, privilegiando a interação socioverbal e a relação intersubjetiva. Os dados foram coletados longitudinalmente ao longo de um ano e quatro meses e as produções linguísticas de uma criança com paralisia cerebral de quatro anos e dois meses de idade foram analisadas de uma perspectiva discursiva. Assim, distantes de avaliações e tratamentos mensuráveis, os quais se pautam em tarefas mecânicas de codificação e decodificação de palavras isoladas, nossa pesquisa pautou-se na análise processual da construção conjunta da significação. Tal análise nos permite afirmar que, mediante o processo interlocutivo, essa criança ampliou seu papel no diálogo. Observamos como ela, de um momento inicial em que apresentava apenas fragmentos de enunciados, passou a estruturar narrativas mais completas.
\end{abstract}

Palavras-chave: Paralisia cerebral; discurso; pesquisa qualitativa.

\section{CLINICAL-QUALITATIVE ANALYSIS OF THE DISCOURSE OF A CHILD WITH CEREBRAL PALSY}

\begin{abstract}
This article proposes a reflection on the establishment of procedural linguistic-discursive production of a child with cerebral palsy in the light of interactive situations. It presents clinic qualitative method as a way of linguistic-discursive investigation and intervention, emphasizing a social verbal interaction and a subjective relationship. The data was longitudinal collected during one year and four months and the linguistic productions of a four-year-old child were analysed in a discursive perspective. Therefore, faraway from measurable evaluations and treatments, which are based in mechanic tasks of words codification and de-codification, our research was based in a group process significant construction analysis. Such analysis allow us to affirm that this child amplify her role in the dialogue. Thus, we observe that in the beginning of the process the child presented a fragmented discourse, and after all she presented complete structured narratives.
\end{abstract}

Key words: Cerebral palsy; discourse; qualitative research.

\section{ANÁLISIS CLINICO-CUALITATIVO DEL DISCURSO DE UN NIÑO CON PARÁLISIS CEREBRAL}

RESUMEN. Ese artículo propone una reflección sobre la constitución procesual de producciones linguístico-discursivas de un niño con parálisis cerebral, a la luz de situaciones interactivas. Presenta el método clínico-cualitativo y la investigación como una forma de expresión y de lenguaje, discursivas, con el énfasis en la interacción socio-verbal y en la relación intersubjetiva. Los datos fueron recogidos longitudinalmente más de un año y cuatro meses y la producción linguística de un niño con parálisis cerebral con cuatro años y dos meses de edad fueron analizados bajo una perspectiva discursiva. Por lo tanto, lejos de las evaluaciones y tratamientos que son guiados por medios mecánicos, tareas de codificación y decodificación de palabras aisladas, nuestra investigación se orienta en el análisis del procedimiento de la construcción conjunta de significado.

Palabras clave: Parálisis cerebral; discurso; investigación cualitativa.

\footnotetext{
* Doutora em Lingüística. Docente da graduação em Fonoaudiologia e do Mestrado e doutorado em Distúrbios da Comunicação na Universidade Tuiuti do Paraná.

\# Mestranda em Distúrbios da Comunicação da Universidade Tuiuti do Paraná.
} 
O termo paralisia cerebral vem sendo utilizado, na literatura médica, para designar uma enfermidade caracterizada por alterações motoras provenientes de uma lesão não progressiva do encéfalo imaturo. A primeira descrição dessa patologia foi feita em 1853 (Leitão, 1971). Conforme tal descrição, essa patologia apresenta-se a partir de uma lesão que interfere no processo maturativo do sistema nervoso central, ou seja, antes, durante ou após o nascimento até que se complete a maturação neurológica. Convém esclarecer que, apesar de a área médica considerar como essencial, na caracterização da paralisia cerebral, o fato de a lesão ocorrer em um encéfalo imaturo, há controvérsia entre autores no que se refere à definição de uma faixa etária capaz de determinar a época em que o sistema nervoso central atinge o seu desenvolvimento pleno. Leitão (1971) sugere como data limite 8 anos de idade. Harryman (1990) propõe que tal desenvolvimento atinge seu auge por volta dos 16 anos. Para Duarte (1985), ao contrário, a maturação neurológica é alcançada entre 3 e 5 anos de vida. Não nos deteremos nesse assunto, pois tal discussão está fora do escopo deste trabalho; contudo, vale ressaltar que não existe uma posição conclusiva sobre essa questão, talvez porque a maturação neurológica não dependa somente de fatores biológicos, mas também da atuação do meio social (LaTaille, 1992).

De qualquer forma, a paralisia cerebral é ocasionada por uma lesão neurológica não progressiva e provoca debilitação na coordenação muscular, com resultante incapacidade da criança em manter posturas e realizar movimentos (Bobath, 1990). Embora as sequelas dessa patologia sejam fundamentalmente de ordem motora, existe um elevado índice de sujeitos com essa enfermidade, segundo Rotta (2002), que evidenciam comprometimentos secundários, tais como deficiência mental, alterações auditivas, oculares, visuais e linguísticas. Dentre esses comprometimentos secundários, Achilles (1995) afirma que 86\% dos paralisados cerebrais apresentam alguma dificuldade com a linguagem, e Fischinger (1984) relata que aproximadamente $70 \%$ dos portadores dessa patologia manifestam algum tipo de anormalidade na fala.

A discussão relevante surge quando observamos que a prática clínica tradicional voltada à linguagem prende-se a um diagnóstico classificatório, talvez pela percepção equivocada da fidedignidade que tal diagnóstico oferece, produzindo inevitavelmente as mesmas respostas, independentemente da singularidade dos sujeitos que participam da clínica. Em contraste, Turato afirma que "os estudos qualitativos mostram sua maior força na validade, isto é, no alcance para o qual a medição reflete autenticamente o fenômeno sob exame" (2000, p. 105).

Apesar da neutralidade exigida para se obter a objetividade nas investigações clínico-quantitativas, entendemos ser praticamente impossível ao clínico e pesquisador partir de um referencial neutro, pois ele precisa pautar-se em pressupostos, uma vez que é neles que se apoia, como um compromisso intelectual, emocional e político dentro de cujo contexto ele é orientado a conceber e formular seu saber e seu fazer.

Conforme Turato, nas pesquisas quantitativas há "uma concepção hegemônica das ciências naturais, as quais não têm por escopo estudar os significados que as coisas têm para nós, mas sim, estudar propriamente as coisas - os fenômenos da natureza" (2000, p. 94); ou seja, o foco das pesquisas quantitativas, em geral, recai no produto alcançado, e não no processo percorrido. Esta reflexão se faz necessária por percebemos que as práticas tradicionais de avaliação da linguagem que verificam, por exemplo, as funções perceptuais vinculadas aos canais sensoriais, a função auditiva, o nível intelectual e o desenvolvimento motor oral, voltam-se para os fatores causais que estão interferindo no desenvolvimento linguístico e afastamse do que tomamos como pontos-chave da avaliação: o sujeito paralisado cerebral, o significado e o processo terapêutico.

Além disso, ao se propor uma avaliação de linguagem e procedimentos terapêuticos uniformizados conforme apresentados por Tabith (1989), igualam-se todos os sujeitos e toma-se a linguagem como código de comunicação estanque, o qual estaria na simples dependência de emissão (codificação) e recepção (decodificação) de mensagens. Cabe ressaltar que essa concepção redutora de linguagem é observada ainda hoje na prática clínica de alguns fonoaudiólogos e psicólogos, mas desde a década de 1980 vários pesquisadores já repensaram essas questões e passaram a refletir sobre a linguagem a partir de bases teóricas voltadas para a própria linguagem. (Berberian, Bortolozzi \& Guarinelo, 2006; Tonochi, Berberian \& Massi, 2008; Pan, 2008).

Neste sentido, dependendo da concepção de linguagem e de sujeito que tenha o clínico/pesquisador, o diagnóstico de uma criança paralisada cerebral com atraso na linguagem pode ser compreendido como um fato em si mesmo, evidenciado na especificidade do diagnóstico ou, como pretendemos propor ao longo deste artigo, em função da singularidade do sujeito em questão. Conceber tal singularidade significa conhecer cientificamente o particular no seu processo de relação 
intersubjetiva, ou seja, no seu processo de desenvolvimento da linguagem.

Exatamente porque os significados dos fenômenos analisados são determinantes para o clínico envolvido com a singularidade de cada sujeito e para pesquisadores qualitativos, como afirmam Turato (2003, 2005) e Guerriero (2008), o objetivo principal deles é capturar tais significados ouvindo, observando e interpretando o sujeito avaliado. Desta forma esse investigador realça o modo como a experiência social é criada e adquire significado, enfatizando a natureza repleta de valores da investigação. (Denzin \& Lincoln, 2006). Por isso entendemos que a investigação clínica qualitativa possibilita ao investigador sair da posição de quem fala de um objeto para assumir o papel de quem fala com um sujeito, por meio de investigação minuciosa e reflexiva sobre a relação sujeito investigador-clínico e paciente investigado. Para Freitas (2002, p. 24), "inverte-se, desta maneira, toda a situação, que passa de uma interação sujeito-objeto para uma relação entre sujeitos, ou seja, de uma orientação monológica, passa-se a uma perspectiva dialógica". Ainda, segundo Freitas (2002, p. 24)

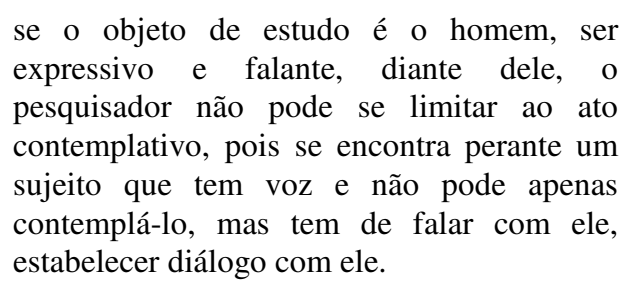
expressivo e falante, diante dele, o pesquisador não pode se limitar ao ato contemplativo, pois se encontra perante um sujeito que tem voz e não pode apenas contemplá-lo, mas tem de falar com ele, estabelecer diálogo com ele.

Nas humanidades e principalmente em se tratando da linguagem, entendemos que o processo é uma ideia-chave. Como dois lados de uma mesma moeda, a investigação e o trabalho terapêutico são inseparáveis por natureza. Por isso uma costura se faz necessária: o papel do sujeito enquanto investigador e o papel do sujeito enquanto paciente (não no sentido estrito) são os lados complementares do processo terapêutico.

O termo processo é bem pontual, até porque é no próprio processo que se dá a comunhão dos métodos, uma vez que é lá que se encontram o sujeito/investigador clínico e o sujeito/paciente paralisado cerebral. "Entendendo por metodologia o caminho e os instrumentais próprios da abordagem da realidade, neste sentido a metodologia ocupa lugar central no interior das teorias sociais, pois ela faz parte intrínseca da visão social de mundo veiculada na teoria" (Minayo, 1999, p. 22).

A partir do pressuposto teórico da interação intersubjetiva, que assume a linguagem como constitutiva do sujeito, torna-se possível a formação dos fios em uma mesma rede: processo investigativo, por um lado, e processo terapêutico, por outro. De um lado da moeda, o investigador clínico-qualitativo (que interpreta e privilegia o significado e o processo) pressupõe, do outro lado, um sujeito paralisado cerebral que age, pensa, sente e existe. Este, que é o paciente, é um agente enunciador no diálogo, pois passa a constituir-se como um sujeito na atividade linguística.

A pesquisa clínico-qualitativa

é um método concebido como um meio
científico de conhecer e interpretar as
significações - de naturezas psicológicas e
psicossociais - que os indivíduos [pacientes
ou quaisquer outras pessoas preocupadas ou
que se ocupam com problemas da saúde, tais
como a equipe de profissionais, aos
familiares e pessoas da comunidade], dão aos
fenômenos do campo da saúde-doença
(Turato, 2003, p. 240).

Assim, a investigação clínico-qualitativa responde a uma possibilidade de defender a compreensão no diálogo como determinante de um saber científico e de um fazer clínico, pois, segundo Denzin e Lincoln (2006), a compreensão é entendida como atividade participativa e, por isso, dependente de um processo dialógico. Entendemos que tal processo é "condição sine qua non para a apreensão de conceitos que permitem aos sujeitos compreender o mundo e nele agir (...) Portanto, é crucial dar à linguagem o relevo que de fato tem" (Geraldi, 1997, p. 5).

É na linguagem que os significados constroem os eventos, ou seja, tecem uma união entre os interlocutores. A linguagem, tomada como evento, só tem consistência na singularidade do momento em que se enuncia (Geraldi, 1997). Assim, ao entendermos que, nessa perspectiva, os eventos fundam uma historicidade e criam uma contrapalavra do interlocutor (e vice-versa), a palavra ultrapassa o seu tema puro, pois sua significação é inseparável da situação concreta em que se realiza.

Segundo Franchi (1992, p.25)

não há nada imanente na linguagem salvo sua força criadora e constitutiva (...) a linguagem não é um dado ou resultado; mas um trabalho que dá forma ao conteúdo de nossas experiências, trabalho de construção, de retificação do vivido que ao mesmo tempo se constitui como simbólico mediante o qual se opera com a realidade.

Entendemos, dessa forma, que a avaliação e o processo terapêutico voltados à linguagem de uma 
criança com paralisia cerebral devem considerar que as possibilidades subjetivas de tal criança são constituídas socialmente pela própria linguagem. Por isso, a atuação clínica não deve afastar a relação que a linguagem dessa criança estabelece com a fala do outro (Massi \& Berberian, 2005; Ramos, 2003; Guarinello \& Gregolin, 2005).

A prática clínica que toma a interação verbal como espaço indispensável para a produção da linguagem percebe que os sujeitos se constituem na interação com os outros e que essa interação se dá no interior de um contexto social e histórico. Ao assumir essa concepção, tal prática clínica afasta-se de procedimentos avaliativos que buscam somente dados de diagnósticos e de métodos terapêuticos prontos e previamente estipulados que pretendem reconstituir, indiscriminadamente, a linguagem desse ou daquele paciente por meio da simples incorporação de um conjunto de itens lexicais ou pela apreensão de regras da gramática.

O fonoaudiólogo, o psicólogo, o médico e outros profissionais, então, levam em consideração o sujeito, suas ações linguísticas e o contexto social das interações verbais (Geraldi, 1997), ou seja, tomam a situação histórico-social como lugar privilegiado onde se dá a interação entre um eu e um tu, e é nesse lugar que os sujeitos produzem discursos. No caso de um clínico que atue com uma criança paralisada cerebral, este pode deslocar o foco da deficiência em si para salientar a criança como um ser em processo de integração social, oferecendo condições para a criança interagir linguisticamente e se constituir enquanto sujeito.

Não se trata da negação do déficit, mas da instauração de um processo terapêutico no qual o déficit deixa de assumir primazia e passa a ser entendido como apenas mais um entre os muitos fenômenos que fazem parte da vida da criança. $\mathrm{O}$ processo terapêutico apoia-se no exercício subjetivo da linguagem, na atuação conjunta entre o terapeuta e a criança, ou seja, entre duas pessoas concretas e singulares, com suas próprias histórias de vida situadas em um meio social.

Destarte, com o objetivo de propor uma reflexão sobre a constituição processual do discurso, analisamos, à luz de situações interativas, produções linguísticodiscursivas de uma criança com paralisia cerebral a partir de uma perspectiva clínico-qualitativa.

\section{MÉTODO}

Essa pesquisa foi aprovada pelo Comitê de Ética da Universidade Tuiuti do Paraná sob o protocolo número 02/2004. Consiste de um acompanhamento longitudinal da linguagem de uma menina reconhecida pela inicial $\mathrm{G}$, durante um ano e quatro meses, dos quatro anos e dois meses aos cinco anos e seis meses de idade, totalizando 26 sessões de gravação.

Os dados analisados foram obtidos por meio de sessões quinzenais de gravação em fitas cassete, registradas em um ambiente específico de uma escola especializada no atendimento de crianças com paralisia cerebral, situada na cidade de Curitiba/PR. Cada sessão teve duração de aproximadamente 40 minutos. Nos dados que apresentaremos, a identificação da criança e de sua interlocutora é feita por meio das iniciais G. para a criança e INT. para a interlocutora-investigadora, as quais estão devidamente apresentadas na medida em que se enunciam em turnos dialógicos. As sessões foram subdivididas em 26 quadros, identificados de [1] a [26]. Para nossa análise são apresentados somente o primeiro e o último quadros registrados.

Nesses quadros buscamos apreender, a partir de uma perspectiva clínico-qualitativa, na relação intersubjetiva, o percurso que $G$. trilha para desenvolver sua linguagem e, mais especificamente, para desenvolver o discurso narrativo. Assim, os enunciados fragmentados, os progressos, os retrocessos, são analisados à luz das situações interativas estabelecidas entre a criança e sua interlocutora-investigadora.

\section{Caso clínico}

G. é uma menina brasileira, nascida na cidade de Curitiba/Pr em 18/02/91, filha única de um casal de baixo poder aquisitivo e instrução primária. Logo ao nascer, desenvolveu uma grave icterícia, ficando internada em um hospital de Curitiba. Em 16/04/93 foi submetida a uma avaliação elaborada por uma equipe multiprofissional - composta por uma psicóloga, uma fonoaudióloga, um fisioterapeuta e uma assistente social - em um centro de atendimento voltado a pessoas com múltiplas deficiências, a qual apresentou o seguinte diagnóstico: "Criança com dois anos e dois meses de idade, portadora de paralisia cerebral, manifestando-se clinicamente por incoordenação motora com predomínio em eixo corporal, tendo por provável etiologia quadro de hiperbilirrubinemia neonatal, sendo que os níveis cognitivos são compatíveis com a idade cronológica, apresentando ainda um atraso no desenvolvimento da linguagem".

Com relação especificamente ao diagnóstico que atesta ter a criança um atraso de linguagem, cabem algumas considerações. Do ponto de vista dialógico e clínico-qualitativo, afirmar que uma criança tem atraso no desenvolvimento da linguagem não nos ajuda a 
compreender o seu caso, as suas particularidades, as (im)possibilidades linguístico-discursivas, conforme discutimos na análise dos dados apresentada na sequência. De momento, convém esclarecer que um diagnóstico de atraso de linguagem parte de uma visão classificatória e comparativa que nos distancia do sujeito avaliado e o insere em uma categoria diagnóstica geral que não nos possibilita entender especificamente suas dificuldades. Em outras palavras, é um diagnóstico que, em si, não ajuda o clínico a organizar um procedimento terapêutico, na medida em que não indica o que precisa ser trabalhado terapeuticamente do ponto de vista da linguagem, ou seja, não aponta que nível linguístico merece atenção clínica: o fonético, o fonológico, o sintático, o discursivo, o semântico, o pragmático, ou uma combinação deles, dependendo do caso de cada criança e de sua história de relação com a linguagem.

Depois de ser avaliada e receber um parecer diagnóstico amplo, G. foi encaminhada para uma escola especializada no atendimento de portadores de paralisia cerebral, na qual ingressou em 28/04/93, passando a receber atendimento fonoaudiológico, psicológico, fisioterápico e pedagógico.

Antes do início da coleta, procuramos os pais e a fonoaudióloga da escola para que pudéssemos conversar sobre a $\mathrm{G}$. A fonoaudióloga nos relatou que a criança apresentava um retardo de linguagem acompanhado de disartria que estava desenvolvendo com G. atividades que visavam ao reconhecimento, discriminação e nomeação de partes do corpo, de noções espaçotemporais, de cores e formas, além de estar encaminhando uma prática voltada para a adequação de órgãos fonoarticulatórios.

$\mathrm{Na}$ conversa com a mãe, esta nos revelou que encontrava dificuldades em aceitar a deficiência da filha. Relatou ainda que, além de conviver com os pais, G. também tem muito contato com os avós maternos, que gosta de brincar com os primos e com outras crianças da vizinhança.

Ao final da conversa, perguntamos à mãe: "Você brinca bastante com a G.?” - e a mãe respondeu: "Não, eu não tenho esse costume, eu cuido dela, dou comida, banho (...), gosto de vê ela sempre limpinha, mas não brinco com ela". E completou: "Eu tenho muita peninha dela". Os relatos apresentados acima nos ajudam a entender um pouco da história da G. As informações da mãe e da fonoaudióloga nos ajudam a compreender como G. está sendo concebida socialmente pela mãe e por essa profissional que a está atendendo.

A mãe confessa ter pena da condição da filha e afirma que sua preocupação volta-se para a alimentação e para a higiene de G. Ela relata que não consegue brincar e interagir com a criança, ou seja, que tem dificuldade em colocar G., dialogicamente, na posição de sujeito do discurso. Cabe esclarecer que não estamos querendo julgar a mãe - ao contrário, buscamos entender qual o lugar que eselasa mãe está conseguindo dar a $\mathrm{G}$.

A fonoaudióloga, por sua vez, ao relatar as atividades que desenvolve com G - como reconhecimento, discriminação e nomeação de partes do corpo, de noções espaçotemporais, de cores e forma, aponta claramente para uma concepção de linguagem distanciada de uma perspectiva dialógica, pois privilegia um tratamento quantificado de progressão de determinadas habilidades e não se envolve com situações interativas nas quais $G$ possa assumir o papel de interlocutora e na/pela linguagem constituir-se como sujeito capaz de significar o mundo e a si própria. Os relatos apresentados pela mãe e pela fonoaudióloga nos ajudam a entender $o$ posicionamento assumido por G. nas situações interativas, apresentadas na sequência.

$\mathrm{Na}$ época em que começamos a coletar os dados, G. já conhecia a interlocutora-investigadora, uma fonoaudióloga pautada em uma perspectiva dialógica, completamente distante da posição assumida pela fonoaudióloga anteriormente responsável pelo caso, cuja atuação foi brevemente comentada acima. Elas (a interlocutora-investigadora e G) já haviam brincado juntas várias vezes. Quando se encontraram para a primeira sessão de gravação já tinham estabelecido algum vínculo. Ao entrar na sala em que estava sua interlocutora, a criança agiu com desenvoltura e começou a mexer em alguns brinquedos expostos.

\section{RESULTADOS E DISCUSSÃO}

Quadro [1]: (18/04/95). (os dados foram transcritos ortograficamente, levando em conta a interação estabelecida entre $\mathrm{G}$ e sua interlocutora)

01 - INT - Como que é teu nome?

02 - G.- É Échica.

03 - INT - É Géssica?

$04-$ G. $-E$.

05 - INT - O que que cê tá fazendo aqui?

06 - G. - Cola. (escola)

07 - INT - Você veio p'ra escola?

Pausa (sem resposta)

08 - INT - Como é o nome da tua mãe?

09 - G. - Ice.

10 - INT - Como? 
11 - G.- Enice

12 - INT - Cleonice?

13 - G. - É.

14 - INT - Onde que ela tá?

15 - G.- Tá caca (está em casa).

16 - INT - Onde?

17 - G.- Tá casa.

18 - INT - Tá em casa? ... hum ... e como é que você vai para casa?

19 - G. - Di obu (de ônibus).

20 - INT - Como?

21 - G. - Di õibu (reforça a pronúncia).

22 - INT - Você já foi na sala da tia Sandra hoje?

G. - (faz sinal de positivo com a cabeça)

23 - INT - Então diga: já.

24 - G. - Já.

25 - INT - E onde mais você foi hoje?

26 - G. - A Lã (na Lílian).

27 - INT - Onde?

28 - G. - Iiã. (Lílian);

29 - INT - Na Lílian fazer físio?

G. - (não responde e volta seu olhar para um aviãozinho de brinquedo).

30 - INT - Você quer pegar teu avião?

G. - (acena positivamente)

31 - INT - Então fale.

32 - G. - Ahã.

33 - INT - Diga: Quero pegar meu avião.

34 - G. - Qué cá aião (vai em busca do brinquedo).

35 - INT - Como é o nome de tua professora?

36 - G. - Lãa (Lãna).

37 - INT - Lãna? Onde está a Lãna?

38 - G. - A á (está lá).

39 - INT - Onde?

40 - G. - Tá á (melhora a pronúncia).

41 - INT - Está na sala?

42 - G.- $E$ (em seguida, olha para o chão e aponta para o seu sapato).

43 - INT - Você está de sapato?

G. - (faz sinal positivo com a cabeça)

44 - INT - Então diga!

45 - G. - Eu tô... igal ca Caína.

46 - INT - Igual da Carina?

G.- (mostra sua unha pintada).

47 - INT - O que que é isso aqui?

48 - G. - A unha!

49 - INT - Quem que pintou?

50 - G. - A bó. (a vó).
51 - INT - A vó pintou a tua unha?

52 - G. - $E$ (volta-se para o gravador, fazendo menção que cansou de gravar).

53 - INT - Você quer ouvir agora?

G. - (acena que sim).

54 - INT - Então diga: quero!

55 - G. - Eu quéo.

Partindo de uma perspectiva discursiva, percebemos, no quadro [1], que G. é capaz de preencher os turnos conversacionais, cumprindo seu papel na interação. A maior participação da investigadora é evidente e consiste em dirigir à criança perguntas que, respondidas, favorecerão o processo de desenvolvimento do discurso narrativo.

Perguntas do tipo “Onde?", "Quem?” e "O quê?” originam a constituição da narrativa. As duas primeiras constituem uma preparação para o que é chamado de sessão-orientação da narrativa. De forma diferente, perguntas do tipo: "O quê?" podem servir para marcar a sessão-complicação (Labov \& Waletesky, 1967). No quadro [1], esses três tipos de perguntas aparecem com frequência na fala da interlocutora adulta e, apesar de não desenvolver narrativas a partir de tais perguntas, a criança mostrouse capaz de respondê-las, preenchendo seus turnos.

Aliás, dos 55 turnos apresentados neste quadro, somente o 07 e o 09 não receberam respostas da criança, deixando lacunas que talvez possam ser entendidas se considerarmos que as perguntas da investigadora foram mal selecionadas. Em 07 a investigadora pergunta: "Você veio p'ra escola?". Porém, ambas as interlocutoras estavam na escola, naquele momento e sabiam que a criança tinha vindo até a escola. Da mesma forma, em 29, a interlocutora quer saber se a criança foi fazer fisioterapia na sala da tia Lílian, mas G. já havia dito que tinha ido à sala da Lílian. Tanto a criança como a adulta conheciam o funcionamento do setor de fisioterapia. A Lilian, fisioterapeuta da escola, atende as crianças com horário marcado e ninguém é encaminhado até a sua sala se não for para fazer fisioterapia; portanto, se G. respondeu que tinha ido à sala da Lílian, estava implícito em sua afirmação que fez fisioterapia.

Entre os turnos 43 e 46, a criança conta que o seu sapato é igual ao de sua colega. Apontando para o seu sapato, objeto que estava presente no momento do diálogo, ela relata, com auxílio de sua interlocutora, algo singular: "eu tô de sapato igual ao da Carina". Esse dado torna-se mais relevante ao considerarmos que a própria criança, ao apontar para seu sapato, toma a iniciativa de mostrá-lo e compará-lo com o de sua amiga, desencadeando uma construção conjunta. 
O mesmo ocorre entre os turnos 47 e 52 . Ao mostrar sua unha pintada, G. acaba por desencadear outra construção conjunta: a vó pintou a unha. Nessa construção ela compartilha com sua interlocutora uma experiência pessoal vivenciada antes da atividade dialógica e, além disso, mostra que sabe usar verbos no perfeito, relatando um evento ocorrido no passado.

O fato de a interlocutora adulta solicitar da criança respostas verbais, como ocorre em $23,31,33$, 44 e 54, deve-se a uma questão que merece maiores esclarecimentos. G. é encarada por muitos como uma "pobre deficiente". Essa atitude evidencia-se, inclusive, na postura adotada pela própria mãe, em sua relação com a criança. Assim, G. coloca-se em uma situação cômoda, na qual não precisa se esforçar, falar, saber. Todos os gestos que faz são aceitos e prontamente atendidos.

O objetivo da interlocutora, ao cobrar dela uma resposta verbal, é exatamente colocá-la numa posição em que precise fazer uso da linguagem. Em 24, 32, 34, 45 e 55 ela acaba por ceder à solicitação da adulta, mostrando que tem capacidade para tal. Para esclarecermos melhor esta questão, vale rever os três últimos turnos do quadro [1]: a criança demonstra, por meio de gestos, que se cansou de gravar. A interlocutora interpreta seus gestos e pergunta, enfaticamente em 53, se ela quer ouvir a gravação. G. acena que sim. A interlocutora não aceita seu aceno e declara, em 54: "Então diga: quero". Por fim, em 55, a criança responde: "eu quéo"; ou seja, ela retoma parte do enunciado produzido pela adulta e o complementa com o pronome $e u$, marcando a sua presença no discurso.

A análise do quadro [1] mostra que $G$ ainda não constrói narrativas propriamente ditas, provavelmente, pelo não lugar de sujeito que lhe é conferido, tanto na escola, pela fonoaudióloga que a atendia antes do processo terapêutico que está sendo apresentado, como pela própria mãe, que afirmou ter pena da filha. Além disso, ela apresenta uma fala que, do ponto de vista fonológico, denuncia a necessidade de atenção por parte do profissional que a atende.

Nos turnos 10, 16, 20, 37 e 41 a interlocutora repete perguntas já respondidas pela criança com o objetivo de levá-la a perceber a necessidade de articular os sons da fala para que seja compreendida na situação dialógica, e $G$, no uso efetivo da linguagem, mostra-se capaz de melhorar sua articulação, tanto que os turnos 11, 17, 38 e 42 foram preenchidos pela $\mathrm{G}$, que os articulou de forma mais cuidada.

Além disso, apesar de ser portadora de paralisia cerebral, precisamos considerar a surpreendente capacidade da criança em assumir seu papel na atividade dialógica, cumprindo as exigências feitas por sua interlocutora. Ainda que G. tenha apresentado somente fragmentos de enunciados, estes foram suficientes para nos indicar que, com o auxílio de um adulto, ela pode fazer comparações, tomar iniciativa para começar um assunto e (re)constituir situações vivenciadas em momentos anteriores ao da enunciação, construindo pequenos relatos.

Partindo da teoria discursiva, podemos afirmar que um método de avaliação tradicional, pautado na visão de um sujeito passivo e de uma língua/código, teria muito pouco a dizer sobre esses dados. O diagnóstico feito pela fonoaudióloga que estava acompanhando G. anteriormente não nos ajuda a perceber que o caráter fragmentário das produções linguísticas da criança pode ser interpretado como indício de um desenvolvimento linguístico-discursivo que está se concretizando. Conforme apontado anteriormente, tal diagnóstico, que atesta que $\mathrm{G}$ tem um atraso de linguagem, não nos ajuda a vislumbrar as dificuldades e as possibilidades que essa criança apresenta para agir sobre o seu interlocutor com e pela linguagem.

Durante o nosso acompanhamento longitudinal, nos primeiros quadros, G. praticamente limitava-se a responder às perguntas que lhe eram dirigidas. Gradualmente, a partir da relação estabelecida com o outro pela linguagem, ela ampliou seu papel na atividade dialógica: ela passou a fazer perguntas, a propor atividades, a ouvir e a recontar, em conjunto com o adulto, histórias infantis de ficção. Assim, essa menina parece ter entendido a estrutura do discurso narrativo, passando a assumir uma posição de sujeito das situações dialógicas de que participa, nas quais encontra um interlocutor para quem perguntar, contar, relatar.

Entre a gravação do quadro [1] e a do [26] passaram-se aproximadamente 16 meses, nos quais $\mathrm{G}$ e sua interlocutora adulta desenvolveram em conjunto várias e diversificadas situações interativas. Nessas interações, $G$ vai entendendo o jogo interlocutivo. Ela sai da posição de quem simplesmente responde e passa a questionar sua interlocutora. Ela, também, vai entendendo que, por meio da linguagem, pode agir sobre sua interlocutora, propondo-lhe atividades, retomando situações, recuperando discursivamente experiências vivenciadas em momentos anteriores ao da enunciação (Massi, 2001).

Além disso, G passa a envolver-se com narrativas de ficção. Inicialmente, ela simplesmente ouvia as histórias infantis que sua interlocutora contava; em seguida, gradualmente, ela passou a assumir a construção de 
narrativas tradicionais, utilizando elementos linguísticos para introduzir, sequencializar e finalizar a história do Chapeuzinho Vermelho, por exemplo.

No quadro [26], apresentado na sequência, é possível perceber a possibilidade de G. iniciar um relato, dando-lhe continuidade e finalização.

Quadro [26]: (01/07/96). No início da sessão a interlocutora adulta comenta que o seu filho está doente e, na sequência, G. inicia um relato:

01 - G. - Ontem, o tio da Mileide morreu.

02 - INT - Por quê?

03 - G. - Porque ele tava doente.

04 - INT - Por que que ele tava doente?

05 - G. - Daí..

06 - INT - daí, o quê?

07 - G. - Daí ele começô a senti dor de barriga.

08 - INT - Começou a sentir dor de barriga?

$09-$ G. $-\dot{E}$.

10 - INT - E depois?

11 - G. - Daí ele tava ruim.

12 - INT - Ele tava ruim!

13 - G. - Daí ele foi pro hospital.

14 - INT - Foi pro hospital!

15 - G. - É... tirô o coração...

16 - INT - Tirô o coração!... e daí?

17 - G. - Daífoi pro céu.

18 - INT - Daí foi pro céu!

É a partir do relato comentado por sua interlocutora que G. narra este evento singular, no qual é possível notar uma mudança significativa no papel desempenhado pelos interlocutores. A criança assume uma posição mais ampla na atividade dialógica e a sua interlocutora toma uma postura completamente oposta daquela apresentada no quadro [1].

A criança inicia o relato, no turno 01: "Ontem o tio da Mileide morreu.", localizando no passado o evento a ser narrado e determinando o personagem que havia morrido. $\mathrm{O}$ fato de a interlocutora questionar, em 02, por que aquela pessoa morreu, foi suficiente para G. desencadear uma narrativa: "Porque ele tava doente, daí... daí ele começô a sentir dor de barriga, daí ele tava ruim, daí ele foi pro hospital... tirô o coração... daí foi pro céu."

Embora G. não tenha conseguido precisar o fator que originou a morte do personagem, é preciso considerar que ela encadeou, em sequência, seis eventos marcados no passado. Assim, a criança parece mostrar que já é capaz de elaborar um relato, dandolhe início, meio e fim.
No primeiro quadro, nossa criança-sujeito praticamente limitava-se a responder às perguntar que lhe eram dirigidas. Gradualmente, a partir do outro e da linguagem, ela ampliou sua participação no diálogo, assumindo o papel que era recoberto pela sua interlocutora adulta, e, além disso, passou a estruturar seus relatos de experiências pessoais.

Em outras palavras, G. parece ter entendido a estrutura do discurso narrativo. A posição ocupada por G. no episódio [26] é bastante diferente daquela que tomava nas primeiras sessões de gravação, nas quais utilizava apenas fragmentos de enunciados para responder aos questionamentos de seu interlocutor, conforme apresenta o quadro [1].

Por meio deste acompanhamento longitudinal pautado em uma análise clínico-qualitativa, observamos que G. progrediu significativamente nas suas produções discursivas. Confrontando os quadros apresentados, parece ficar claro que as interações linguísticas estabelecidas entre os participantes da prática clínica (a criança e sua interlocutora) levaram G. a assumir um posicionamento mais ativo no diálogo.

A análise dos quadros apresentados nos revela que as produções linguístico-discursivas apresentadas por essa criança ganharam amplitude. Mediante a interlocução, nossa criança-sujeito apresentou progressos significativos no desenvolvimento do discurso narrativo e pôde re(construir) relatos de experiências pessoais, bem como narrativas de ficção, por meio da linguagem. Essa análise revela a importância de considerarmos, na prática de acompanhamentos de linguagem, a interação estabelecida entre a criança e o adulto, a construção conjunta das atividades dialógicas (Santana, 2005). Foi exatamente por meio dessa construção conjunta que a nossa criança-sujeito elaborou - com o outro condições para o exercício da linguagem. $\mathrm{O}$ enfoque clínico-qualitativo nesse percurso nos levou a perceber que, mediante a interlocução, G. ampliou seu papel no diálogo. Observamos claramente como essa criança, de um momento inicial em que apresentava apenas fragmentos de enunciados, passou a estruturar narrativas mais completas, ampliando o seu papel no processo dialógico e convocando seu interlocutor a participar desse processo.

\section{CONSIDERAÇÕES FINAIS}

Com o objetivo de propor uma reflexão crítica sobre uma forma de avaliação e intervenção clínica de linguagem coerente com a possibilidade de vislumbrar 
a constituição processual do discurso, analisamos, à luz de situações interativas, o desenvolvimento linguístico-discursivo de uma criança com paralisia cerebral a partir de uma perspectiva clínico-qualitativa

A análise das produções linguístico-discursivas de G., do ponto de vista processual e à luz de situações interativas, revela-nos a importância de uma discussão metodológica clínico-qualitativa e de um posicionamento teórico que tome linguagem como prática discursiva. $\mathrm{O}$ diagnóstico inicial elaborado para $\mathrm{G}$ (atraso de linguagem) emprega a linguagem da objetividade e do distanciamento, permitindo uma classificação geral do caso; contudo, em conjunto com essa classificação, que pode indicar ao clínico, em linhas gerais, o fato de o paciente observado merecer maior atenção, ressaltamos o trabalho dialógico de constituição da significação linguística em casos de processos terapêuticos envolvendo crianças que apresentam paralisia cerebral.

Nesse sentido, alguns estudos realçam a importância de conhecer a própria criança, sua história de vida e de relação com os outros com quem se relaciona, concedendo-lhe um lugar de destaque. (Guarinello et al., 2006). Percebe-se claramente, no caso apresentado, que o sujeito, o significado e o processo de apropriação da linguagem são enfatizados durante $\mathrm{o}$ transcurso do trabalho investigativo $\mathrm{e}$ terapêutico; ou seja, o prisma clínico-qualitativo, compreendido mediante uma abordagem discursiva da linguagem e da interação socioverbal, viabilizou um procedimento terapêutico que ressalta as possibilidades de nossa criança-sujeito no desenvolvimento de sua linguagem, concedendo-lhe um lugar de sujeito (Maldaner \& Massi, 2006).

$\mathrm{O}$ caso $\mathrm{G}$ ressalta a importância de se analisar a linguagem como um acontecimento interativo portanto, discursivo. Esse acontecimento envolve o ajuste contínuo de imagens que os interlocutores fazem um do outro, bem como o entendimento que esses interlocutores constituem na cadeia dialógica da sociedade em que vivem. É uma construção processual e conjunta da significação, que envolve partilha de informações recíprocas nas quais estiveram envolvidas a criança e uma interlocutora adulta.

Destarte, não entendemos que seria de um lugar afastado e neutro, com atividades previamente estipuladas, que o professor, o fonoaudiólogo ou o psicólogo encontrariam espaço para participar do desenvolvimento linguístico-discursivo de crianças com paralisia cerebral, mas na atividade dialógica que se instaurara no momento da interação. Gostaríamos de encerrar com as palavras de Minayo (1999, p. 16), para quem: saúde e doença exprimem agora e sempre uma relação que perpassa o corpo individual e social, confrontando com as turbulências do ser humano enquanto ser total. São fenômenos clínicos e sociológicos vividos culturalmente. É preciso entender que, ao ampliar suas bases conceituais, as ciências sociais da saúde não se tornam menos científicas, pelo contrário, elas se aproximam com maior luminosidade dos contornos reais dos fenômenos que abarcam.

\section{REFERÊNCIAS}

Achilles, R. (1995). Communicative Anomalies of Individuals with Cerebral Palsy: Analysis of communicative Processes in 151 Cases of Cerebral Palsy. Cerebral Palsy, 2 (16),1524.

Berberian, A.P., Bortolozzi, K.B., Guarinelo, A.C. (2006) Recurso terapêutico fonoaudiológico voltado à linguagem escrita do surdo: o software. Distúrbios da Comunicação, v. (18), 189-200.

Bobath, K. (1990). Uma base neurofisiológica para o tratamento da Paralisia Cerebral. São Paulo: Manole.

Denzin, N. K., Lincoln, Y. S. (2006). O planejamento da Pesquisa Qualitativa: Teorias e Abordagens. Porto Alegre: Artmed.

Duarte, J.P.(1985). Paralisia Cerebral. Em: Lianza, S.(org.), Medicina de Reabilitação (pp. 93-133). Rio de Janeiro: Guanabara Koogan.

Fischinger, B.S. (1984). Considerações sobre a Paralisia Cerebral. São Paulo: Panamed.

Franchi, C. (1992). Linguagem-Atividade Constitutiva. Cadernos de Estudos Linguísticos, 2 (22), 9-39.

Freitas, M. T. A. (2002). A abordagem sócio-histórica como orientadora da pesquisa qualitativa. Cadernos de Pesquisa, 116, 21-39.

Geraldi, J. W. (1997). Portos de Passagem. São Paulo: Martins Fontes.

Guarinello, A.C., Berberian, A.P., Massi, G.A., Santana, A.P., Rivabem, K., Jacob, L.C.B., Machado, M.L.C.A. (2006). Dificuldades de aprendizagem da escrita: uma análise de acompanhamentos clínicos dessa modalidade de linguagem. Revista Letras, 70, 247-266.

Guarinello, A.C., Gregolin, R.M. (2005). As produções escritas de sujeitos surdos. Revista Letras, 65, 135-151.

Guerriero, I. C. Z. (2008). Síntese das reflexões da reunião sobre ética em pesquisa qualitativa em Saúde, Guarujá, SP. Revista Ciência \& Saúde Coletiva, 13, 1-6.

Harryman, S.E. (1990). Paralisia Cerebral. Em: Batshaw, M.L. \& Perret, Y.M. (org.), Criança com deficiência: uma orientação médica (pp. 56-74). São Paulo: Maltese.

La Taille, Y. (1992). Piaget, Vygotsky, Wallon: teorias psicogenéticas em discussão. São Paulo: Summus. 
Labov, W., Waletesky, J. (1967). Narrative analysis: oral version of personal experience. Em: J. Jilm (Org.), Essays on the Verbal and Visual Arts. (pp. 54-87) University of Washington Press: Washington.

Leitão, A. (1971). A paralisia cerebral. Rio de Janeiro: Artenova.

Maldaner, R.D., Massi, G.(2006). O processo de aquisição da oralidade: análise do desenvolvimento do discurso narrativo de uma criança portadora de Síndrome de Down. Revista Fono Atual, 36(9), 64-73.

Massi, G. (2001). Linguagem e paralisia cerebral: Um estudo de caso do desenvolvimento da narrativa. Curitiba: Editora Maio.

Massi, G., Berberian, A. P. (2005). A clínica fonoaudiológica voltada aos chamados distúrbios de leitura e escrita: uma abordagem constitutiva da linguagem. Revista Sociedade Brasileira Fonoaudiologia, 10, 43-52.

Minayo, M. C. S. (1999). O Desafio do Conhecimento: Pesquisa Qualitativa em Saúde. São Paulo: Hucitec.

Pan, M.A.G.S. (2008). O direito à diferença: um estudo sobre deficiência intelectual e educação inclusiva. Curitiba: IBPEX.

Ramos, A.P. (2003). Teoria e prática fonoaudiológica. Revista Distúrbios da Comunicação, 15(2), 335-354.
Rotta, N.T. (2002). Paralisia Cerebral, novas perspectivas terapêuticas. Jornal de Pediatria, (78) 27-39.

Santana, A.P. (2005). O processo de aquisição da linguagem: estudo comparativo de duas crianças usuárias de implante coclear. Revista Distúrbios da Comunicação, 17(2), 233243.

Tabith, A. (1989). Foniatria: disfonias, fissuras labiopalatais, paralisia cerebral. São Paulo: Cortez.

Tonochi, R. C., Berberian, A.P., Massi, G. (2008).A escrita de sujeitos portadores de fissura lábio-palatina. Revista Tuiuti, (39), 41-62.

Turato, E. R. (2000). Introdução à Metodologia da Pesquisa Clínico-Qualitativa - Definição e Principais Características. Revista Portuguesa de Psicossomática, 1, 93-108.

Turato, E. R. (2003). Tratado da metodologia da pesquisa clínico-qualitativa. Petrópolis: Vozes.

Turato, E. R. (2005). Métodos qualitativos e quantitativos na área da saúde: definições, diferenças e seus objetos de pesquisa. Revista de Saúde Pública, 39, 1-9.

Recebido em 29/10/2008 Aceito em 06/08/2009
Endereço para correspondência :
Giselle Massi. Rua Benjamin Lins, 750, ap. 61. Batel. CEP '80420-100, Curitiba-PR, Brasil. E-mail giselle.massi@utp.br. 